\title{
Corrigendum to "Assessment of Hip Fracture Risk Using Cross-Section Strain Energy Determined by QCT-Based Finite Element Modeling"
}

\author{
Hossein Kheirollahi ${ }^{1}$ and Yunhua Luo ${ }^{1,2}$ \\ ${ }^{1}$ Department of Mechanical Engineering, Faculty of Engineering, University of Manitoba, Winnipeg, MB, Canada R3T 5V6 \\ ${ }^{2}$ Department of Anatomy, Southern Medical University, Guangzhou 510515, China
}

Correspondence should be addressed to Yunhua Luo; yunhua.luo@umanitoba.ca

Received 19 April 2017; Accepted 4 May 2017; Published 3 July 2017

Copyright (C) 2017 Hossein Kheirollahi and Yunhua Luo. This is an open access article distributed under the Creative Commons Attribution License, which permits unrestricted use, distribution, and reproduction in any medium, provided the original work is properly cited.

In the article titled "Assessment of Hip Fracture Risk Using Cross-Section Strain Energy Determined by QCT-Based Finite Element Modeling" [1], there was an error regarding the FRAX ${ }^{\circledR}$ tool, which should be clarified as follows:

The article notes: "Fracture Risk Assessment Tool (FRAX) is a tool to evaluate an individual's fracture probability in the next 10 years, adopted by the WHO in 2008 [7]." However, the World Health Organization (WHO) did not develop, test or endorse the $\mathrm{FRAX}^{\circledR}$ tool or its recommendations [2]. The metabolic bone disease unit at the University of Sheffield that developed FRAX $^{\circledR}$ was a WHO Collaborating Centre from 1991 to 2010, but treatment guidelines must undergo a formal process before they can be endorsed by the WHO.

\section{References}

[1] H. Kheirollahi and Y. Luo, "Assessment of hip fracture risk using cross-section strain energy determined by QCT-based finite element modeling," BioMed Research International, vol. 2015, Article ID 413839, 2015.

[2] N. Ford, S. L. Norris, and S. R. Hill, "Clarifying WHO's position on the FRAX ${ }^{\circledR}$ tool for fracture prediction," Bulletin of the World Health Organization, vol. 94, no. 12, p. 862, 2016. 


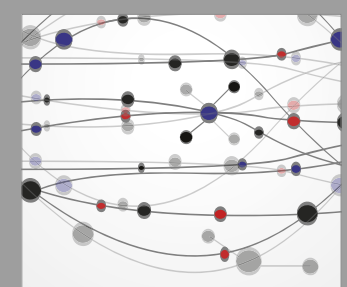

The Scientific World Journal
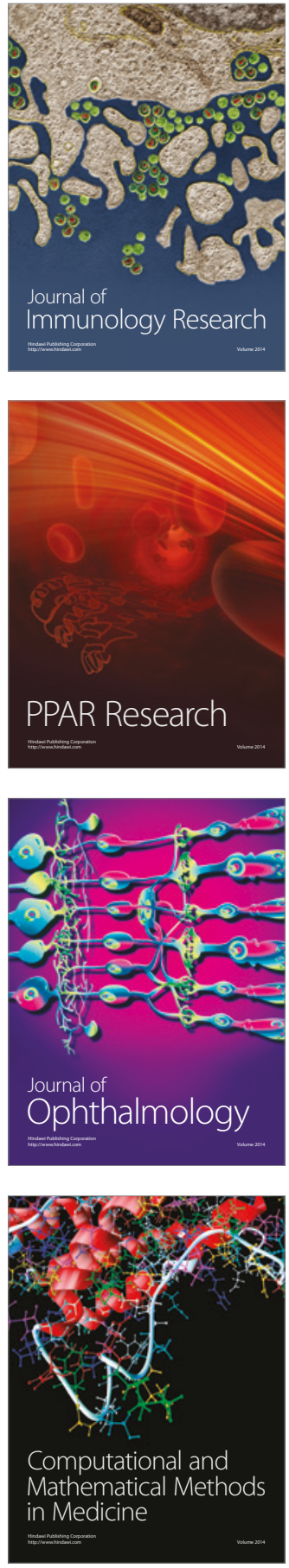

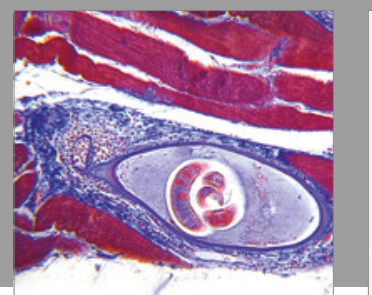

Gastroenterology Research and Practice
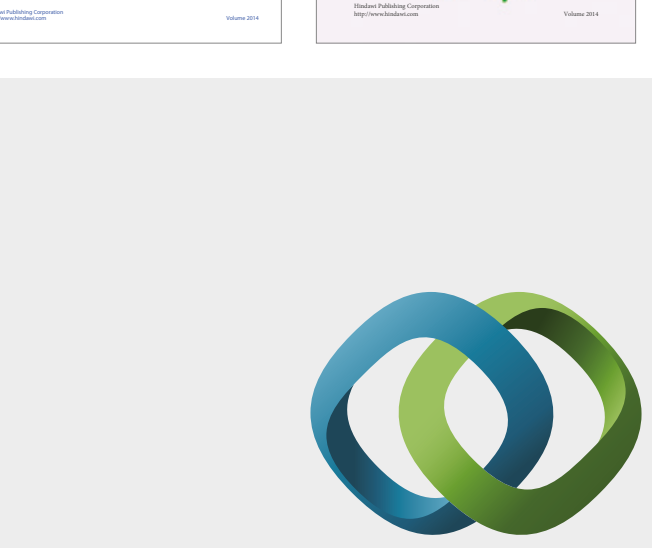

\section{Hindawi}

Submit your manuscripts at

https://www.hindawi.com
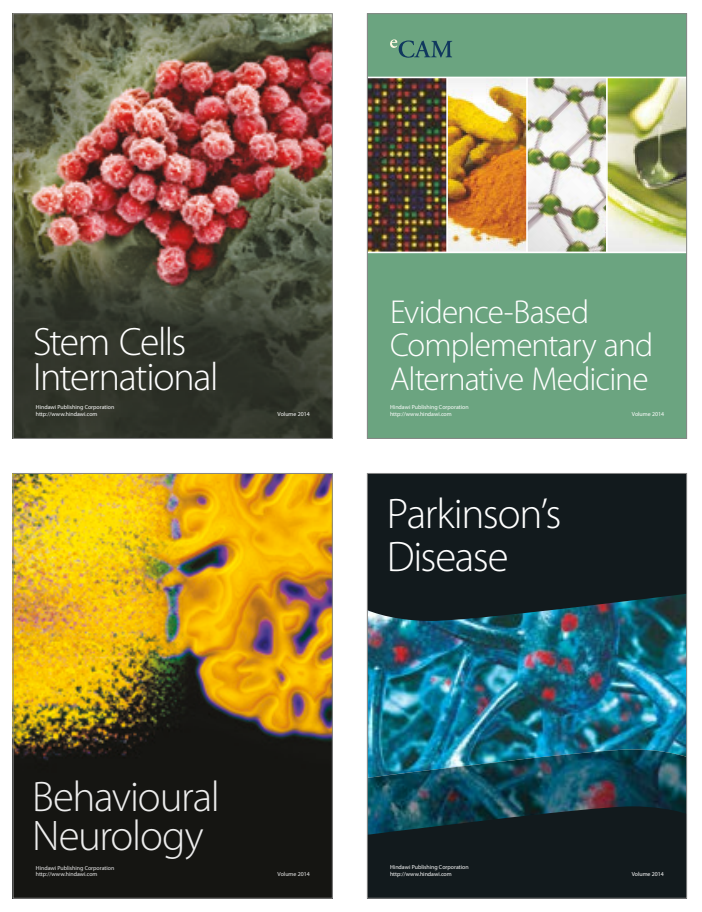
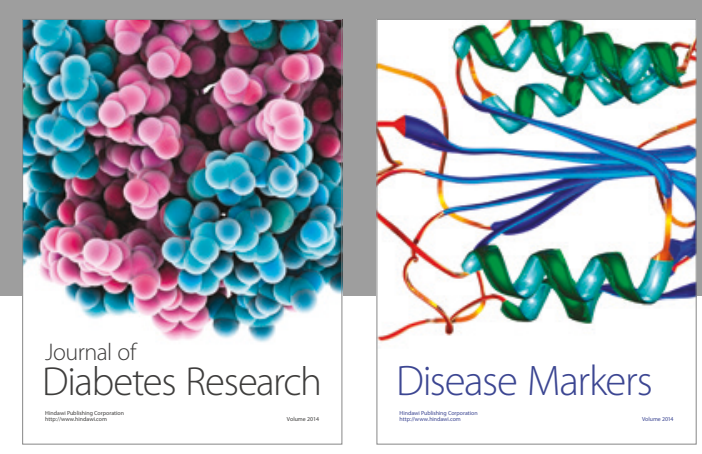

Disease Markers
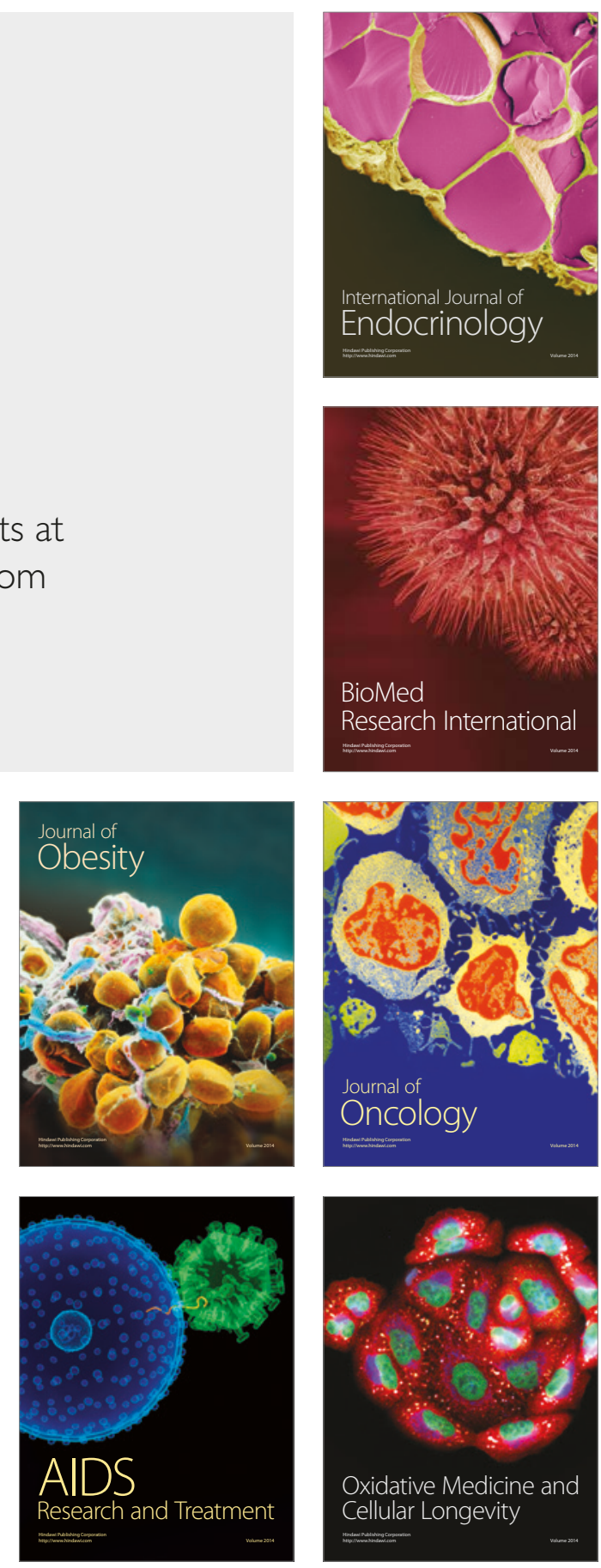